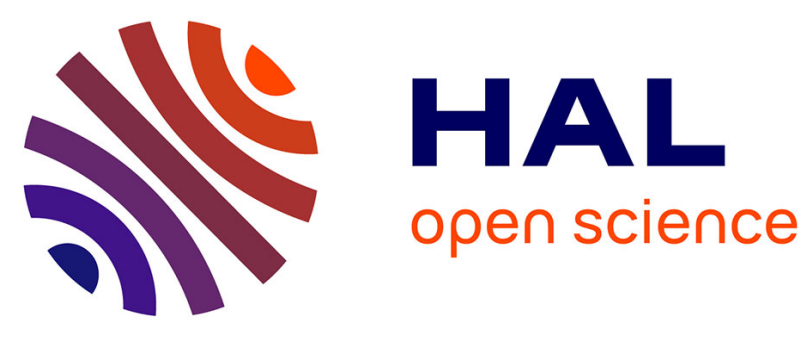

\title{
Use of non-specific intravenous human immunoglobulins in Spanish hospitals; need for a hospital protocol
}

Belen Ruiz-Antorán, Antònia Agustí Escasany, Antoni Vallano Ferraz, Imma

Danés Carreras, Neus Riba, Silvia Mateu Escudero, Joan Costa, Mª Blanca

Sánchez Santiago, Leonor Laredo, José Antonio Durán Quintana, et al.

\section{To cite this version:}

Belen Ruiz-Antorán, Antònia Agustí Escasany, Antoni Vallano Ferraz, Imma Danés Carreras, Neus Riba, et al.. Use of non-specific intravenous human immunoglobulins in Spanish hospitals; need for a hospital protocol. European Journal of Clinical Pharmacology, 2010, 66 (6), pp.633-641. $10.1007 / \mathrm{s} 00228-010-0800-y$. hal-00612990

\section{HAL Id: hal-00612990 https://hal.science/hal-00612990}

Submitted on 2 Aug 2011

HAL is a multi-disciplinary open access archive for the deposit and dissemination of scientific research documents, whether they are published or not. The documents may come from teaching and research institutions in France or abroad, or from public or private research centers.
L'archive ouverte pluridisciplinaire HAL, est destinée au dépôt et à la diffusion de documents scientifiques de niveau recherche, publiés ou non, émanant des établissements d'enseignement et de recherche français ou étrangers, des laboratoires publics ou privés. 


\title{
Use of non-specific intravenous human immunoglobulins in Spanish hospitals; need for a hospital protocol
}

\author{
Belen Ruiz-Antorán • Antònia Agustí Escasany • Antoni Vallano Ferraz • \\ Imma Danés Carreras • Neus Riba • Silvia Mateu Escudero • Joan Costa • \\ $M^{\mathrm{a}}$ Blanca Sánchez Santiago • Leonor Laredo • José Antonio Durán Quintana • \\ Juan Ramón Castillo • Francisco Abad-Santos • Concepción Payares Herrera • \\ Belén Sádaba Díaz de Rada • Eugenio Gómez Ontañón
}

Received: 8 September 2009 /Accepted: 8 February 2010 /Published online: 5 March 2010

(C) Springer-Verlag 2010

Abstract Intravenous immunoglobulin (IVIG) use in nonapproved indications, the increase in consumption and its high cost recommend rationalisation in its utilisation.

Aims To assess the use of IVIG in Spanish hospitals. Methods An observational, prospective and multicentre drug utilisation study was conducted in 13 tertiary Spanish hospitals. Data were collected for 3 months in patients receiving any IVIG. Patient demographics, indication for IVIG use, dosage regimen and cost of treatment were collected.

For the Spanish Group for the Study of the Use of Nonspecific Intravenous Human Immunoglobulines (SUIG) of the Spanish Clinical Pharmacology Society. Prescription profile and development and implementation of a guidance for their correct use. Group members are listed in the Appendix.

B. Ruiz-Antorán $(\bowtie)$

Clinical Pharmacology Department,

Puerta de Hierro Majadahonda University Hospital,

C/ Manuel de Falla 1,

28222 Majadahonda, Madrid, Spain

e-mail: bruiz.hpth@salud.madrid.org

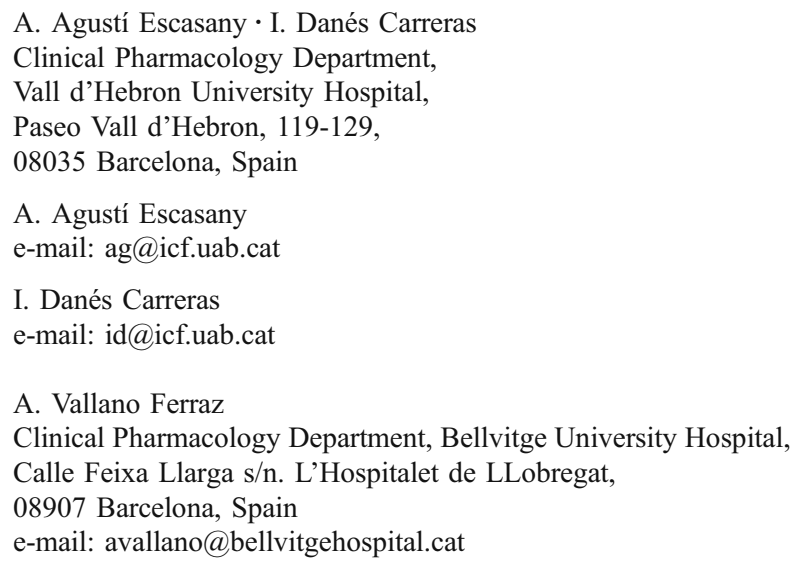

Results Five hundred and fifty-four patients (mean age of 52 years) were included in the study. A total of 1,287 prescriptions were administered, and the average number of prescriptions per patient was 2.3. The mean daily dose was $24 \mathrm{~g}$ (range 0.6-90 g). Overall, IVIG was prescribed for authorised indications in 335 patients $(60 \%)$ with 953 prescriptions (74\%), for non-authorised indications with scientific evidentiary support in 86 patients $(16 \%)$ with 137 prescriptions (11\%), and non-authorised and non-accepted

N. Riba

Clinical Pharmacology Department,

Clínic Hospital,

Calle Villarroel, 170,

08036 Barcelona, Spain

e-mail: NRIBA@clinic.ub.es

\author{
S. Mateu Escudero \\ Clinical Pharmacology Department, \\ Fundació Puigvert, \\ C/ Cartagena 340-350 08025, \\ Barcelona, Spain \\ e-mail: smateu@fundacio-puigvert.es \\ J. Costa \\ Clinical Pharmacology Department, \\ Germans Trias i Pujol University Hospital, \\ Carretera de Canyet s/n, \\ 08916 Badalona, Spain \\ e-mail: jcosta.germanstrias@gencat.cat
}


indications in 133 patients (24\%) with 197 prescriptions $(15 \%)$. The most frequent authorised indications were primary and secondary immunodeficiencies, and the most frequent non-authorised and non-accepted indications were multiple sclerosis and bullous dermatosis. The mean cost of IVIG per patient for authorised indications was 2,636.2€, non-authorised indications with scientific support 5,262.1€ and non-accepted indications 3,555.8 $€$.

Conclusions IVIG is prescribed for a significant number of non-authorised and non-accepted indications with a notable cost. There is an important variability in IVIG prescriptions between hospitals, indicating room for improvement in IVIG use and the need for a consensus of protocol use.

Keywords Intravenous immunoglobulin · Drug utilization study $\cdot$ Off-label use $\cdot$ Compassionate use $\cdot$ Cost

\section{Introduction}

Intravenous immunoglobulin (IVIG), a plasma protein derivative employed in the treatment of a number of conditions, has been increasingly used in medicine over the last two decades [1]. However, only some indications have been authorised by the Spanish Medicines Agency on the basis of contributed evidence. IVIG is also used for a number of conditions not included in the regulatory approvals but for which substantial clinical evidence exists [1]. There has been a significant increase in the price per

\footnotetext{
M. B. Sánchez Santiago

Clinical Pharmacology Department,

Marqués de Valdecilla University Hospital,

Avda. Valdecilla s/n,

39008 Santander, Spain

e-mail: bsanchez@humv.es

L. Laredo

Clinical Pharmacology Department,

Clínico San Carlos University Hospital,

Profesor Martín Lagos, S/N,

28040 Madrid, Spain

e-mail: 1laredo.hcsc@salud.madrid.org

\section{J. A. Durán Quintana}

Clinical Pharmacology Department,

Virgen Macarena University Hospital,

Avda. Doctro Fedriani 3,

Sevilla, Spain

e-mail: jaduran@us.es

\section{J. R. Castillo}

Clinical Pharmacology Department,

Virgen del Rocio University Hospital,

Avda. Manuel Siurot s/n,

Sevilla, Spain

e-mail: juanr.castillo.sspa@juntadeandalucia.es
}

unit of IVIG, due to the increased complexity of manufacturing processes, including safety enhancements and stringent regulatory requirements [2-5]. The capacity to fractionate IVIG from plasma is finite, and regulatory stringency has resulted in major recalls of the product by many of the important worldwide manufacturers. These factors, together with the increase in utilisation, have resulted in significant worldwide shortages of IVIG in the last few years [2-5].

The use of this medicine in non-approved indications, the increase in consumption and its high cost have already promoted the rationalisation of its use through a consensus in other countries. Non-specific IVIG has been the object of a revision from the European Medicines Agency (EMA), and certain indications have been accepted on the basis of contributed evidence and as a result of the companies' request $[6,7]$. Different consensuses and guidelines have attempted to establish priorities and to optimise the use of IVIG with the result that several audits of its usage in a number of different countries have already been published [8-12].

In Spain, according to the legislation that was in force at the time of this study, any drug use outside the conditions established by the Spanish Medicines Agency on the authorised label should be considered "compassionate use." Therefore, off-label drug use should follow all the requirements to get the corresponding authorisation and to be reimbursed by the National Health Service as a nonauthorised medicinal product when prescribed for an individual patient [13].

\author{
F. Abad-Santos \\ Clinical Pharmacology Department, \\ La Princesa University Hospital, \\ Diego de León, 62, \\ Madrid, Spain \\ e-mail: fabad.hlpr@salud.madrid.org \\ C. Payares Herrera \\ Clinical Pharmacology Department, \\ Puerto Real University Hospital, \\ Carretera Nacional IV, Km 665, \\ 11510 Puerto Real, Cadiz, Spain \\ B. Sádaba Díaz de Rada \\ Clinical Pharmacology Department, \\ University Clinic of Navarra, \\ Avenida Pío XII, 36, \\ 31008 Pamplona, Spain \\ e-mail: bsadaba@unav.es \\ E. Gómez Ontañón \\ Clinical Pharmacology Department, \\ University Clinic of Canarias, \\ Ofra $\mathrm{s} / \mathrm{n}^{\circ}$-Ctra. La Cuesta, \\ 38320 La Laguna, Tenerife, Spain \\ e-mail: egomez@huc.canarias.org
}


In this regulatory/legal setting, the Spanish Society of Clinical Pharmacology considered it to be of interest to carry out a study describing the utilisation of IVIG in Spain. The purpose of this study was to describe the use of IVIG in a number of Spanish hospitals and to evaluate the justification/rationale behind that use, according to a set of previously established criteria. Secondary objectives were to describe the different administrative patterns in the different situations faced (whether informed consent was obtained, if the corresponding authorisations for compassionate use were obtained, among others), the adverse events profile, the economic quantification of IVIG use, and the variability of use among different hospitals. The main hypotheses of the study were that a considerable percentage of IVIG prescriptions would be for off-label indications, especially for nonapproved non-accepted indications, suggesting unnecessary health expenditure. A certain variability in IVIG prescriptions between hospitals was expected.

\section{Methods}

An observational, prospective and multicentre drug utilisation study was carried out in 13 tertiary Spanish hospitals. Data were collected in each centre over a period of 3 months between July of 2004 and January of 2005 .

All patients who received any of the IVIG drugs (Flebogamma ${ }^{\circledR}$, Endobulin ${ }^{\circledR}$, Gammagard ${ }^{\circledR}$ ) were included in the study regardless of their age, sex, reason for the prescription, dose and duration of treatment, or concomitant drugs.

By means of a structured questionnaire, information on patient's demographics, indication for IVIG use, dosage regimen, adverse drug reactions, reasons for treatment withdrawal and requested informed consent were gathered from the medical records. Other data about administrative parameters, authorisation of compassionate use and batch identification as well as the cost of IVIG use were supplied by the pharmacy service of every hospital participating in the study. In addition, data of the participant hospitals were recorded.

An ad hoc appropriateness analysis of IVIG indications was performed according to IVIG indications established by the EMA [6, 7], recommendations of expert panels for offlabel use and the published scientific evidence [14-32]. For the aforementioned analysis, the indications were classified in three groups: authorised by the EMA (group 1), nonauthorised indications with scientific evidentiary support (level A (Oxford Centre for Evidence-based Medicine): at least one controlled and randomized clinical trial that was appropriately designed supports IVIG use) (group 2) (Table 1) and finally the others were considered as nonauthorised and non-accepted indications (group 3). For the last two groups, informed consent and the Spanish compassionate use procedure were required. The definition of compassionate use in Spain is a special and unique requirement that applies to drug use (1) in patients outside a clinical trial with an investigational medicinal product and (2) for indications or conditions different from those authorised in the summary product characteristics ("off-label" use) [13].

The cost of IVIG use was calculated from the price information supplied by the financial department of every hospital participating in the study.

The study was conducted according to international ethics recommendations. In accordance with the national directives in relation to post-authorisation studies, the study was approved by the Ethics Committee of Clinical Investigation of the coordinating hospital and additionally by the remaining hospitals whenever required.

Statistics analysis Data were entered in a relational database (Microsoft Access, Microsoft, Redmond, WA). Descriptive analysis of continuous variables was performed by means of mean, standard deviation, median and range. The statistical analysis was performed using SAS version 9 statistical package.

Table 1 Classification of indications according to the authorisation by the EMEA and scientific evidentiary support

\begin{tabular}{ll} 
Authorised indications by the EMEA & Non-authorised indications with scientific evidentiary support \\
\hline Primary immunodeficiencies & Myasthenia gravis \\
Secondary immunodeficiencies & Chronic inflammatory demyelinating polyradiculopathy \\
$\quad$ Chronic lymphoid leukaemia & Motor multifocal neuropathy \\
$\quad$ Multiple myeloma & Dermatomyositis \\
$\quad$ Medulla osseous transplant & Pure red cell aplasia parvovirus B19 \\
Idiopathic thrombocytopenic purpura & Lambert-Eaton syndrome \\
Kawasaki syndrome & Thrombocytopenia refractory to transfusions \\
Guillain-Barré syndrome & Interstitial pneumonia CMV, in BMT patients \\
Isoimmunization & \\
Children with congenital AIDS and recurrent infections &
\end{tabular}

BMT: Bone Marrow Transplantation 
Table 2 IGIV prescriptions in the authorised indications

\begin{tabular}{|c|c|c|c|c|}
\hline \multirow[t]{2}{*}{ Indications } & \multicolumn{2}{|l|}{ Patients } & \multicolumn{2}{|l|}{ Prescriptions } \\
\hline & $\begin{array}{l}\text { Authorised indications } \\
(n=335)(\%)\end{array}$ & $\begin{array}{l}\text { All indications } \\
(n=554)(\%)\end{array}$ & $\begin{array}{l}\text { Authorised indications } \\
(n=953)(\%)\end{array}$ & $\begin{array}{l}\text { All indications } \\
(n=1,287)(\%)\end{array}$ \\
\hline Primary immunodeficiencies & 50.4 & 30.5 & 58.1 & 43.0 \\
\hline Secondary immunodeficiencies ${ }^{\mathrm{a}}$ & 27.8 & 16.8 & 28.9 & 21.4 \\
\hline Idiopathic thrombocytopenic purpura & 10.1 & 6.1 & 6.3 & 4.7 \\
\hline Kawasaki syndrome & 0.9 & 0.5 & 0.3 & 0.2 \\
\hline Guillain-Barré syndrome & 7.2 & 4.3 & 2.8 & 2.1 \\
\hline Isoimmunization & 0.9 & 0.5 & 0.3 & 0.2 \\
\hline Congenital AIDS & 2.7 & 1.6 & 3.3 & 2.4 \\
\hline
\end{tabular}

${ }^{\text {a }}$ Chronic lymphoid leukaemia, multiple myeloma and medulla osseous transplant

\section{Results}

During the study period, data from the 554 patients treated in the participating hospitals were collected. Patients had a mean age of 52 years $( \pm 16)$, and $54 \%$ were female. It should be noted that the patient population included a group of 87 children and adolescents (15.7\%).

A total of 1,287 prescriptions were administered during the study period, representing 2,352 days of treatment. The average number (SD) of days of treatment was 1.7 (1.4), with a median of 1 day (range 1-11 days). The average number (SD) of prescriptions per patient during the study period was 2.3 (1.6), with a median of 2 prescriptions (range 1-13). A total of 238 patients (43\%) received one IVIG prescription, 99 patients $(17.9 \%)$ two prescriptions, $96(17.3 \%)$ three prescriptions, 82 (14.8\%) four prescriptions, and $39(7 \%)$ five or more prescriptions. The treatment with IVIG was initiated during the study period in 174 (31.4\%) patients, before the study period in
344 patients $(62.1 \%)$ and in 36 patients $(6.5 \%)$ the timing was unknown.

The most frequently prescribed IVIG was Flebogamma (654, 50.8\%), followed by Endobulin (583, 45.3\%) and Gammagard (50, 3.9\%). The mean (SD) daily dose was 24 (14.8) g, with a median of $22.5 \mathrm{~g}$ (range $0.6-90 \mathrm{~g}$ ). The IVIG were most frequently prescribed by the neurology (131 patients and 187 prescriptions), haematology (125 patients and 332 prescriptions) and pneumology (104 patients and 365 prescriptions) services.

Overall, 335 patients $(60 \%)$ were prescribed IVIG for labelled indications authorised by the EMEA (group 1), while $219(40 \%)$ received them for off-label indications (groups 2 and 3). In the off-label indications, 86 patients $(39.2 \%)$ were included in group 2 (non-authorised indications with scientific evidentiary support), and 133 patients $(60.7 \%)$ in group 3 (non-authorised and non-accepted indications) There were 953 (74\%) prescriptions of IVIG for authorised indications, 137 (11\%) for non-authorised

Table 3 IGIV prescriptions in non-authorised indications with scientific evidentiary support

\begin{tabular}{|c|c|c|c|c|}
\hline \multirow[t]{2}{*}{ Indications } & \multicolumn{2}{|l|}{ Patients } & \multicolumn{2}{|l|}{ Prescriptions } \\
\hline & $\begin{array}{l}\text { Non-authorised indications with } \\
\text { scientific evidentiary support } \\
(n=86)(\%)\end{array}$ & $\begin{array}{l}\text { All indications } \\
(n=554)(\%)\end{array}$ & $\begin{array}{l}\text { Non-authorised indications with } \\
\text { scientific evidence support } \\
(n=137)(\%)\end{array}$ & $\begin{array}{l}\text { All indications } \\
(n=1,287)(\%)\end{array}$ \\
\hline Motor multifocal neuropathy & 24.4 & 3.8 & 30.7 & 3.3 \\
\hline Myasthenia gravis & 29.1 & 4.5 & 24.8 & 2.6 \\
\hline $\begin{array}{l}\text { Chronic inflammatory demyelinating } \\
\text { polyradiculopathy }\end{array}$ & 22.1 & 3.4 & 19.7 & 2.1 \\
\hline Dermatomyositis & 14.0 & 2.2 & 13.1 & 1.4 \\
\hline Pure red cell aplasia parvovirus B19 & 2.3 & 0.4 & 5.1 & 0.5 \\
\hline $\begin{array}{l}\text { Interstitial pneumonia } \mathrm{CMV} \text { in } \mathrm{BMT} \\
\text { patients }\end{array}$ & 4.6 & 0.7 & 3.6 & 0.4 \\
\hline $\begin{array}{l}\text { Thrombocytopenia refractory to } \\
\text { transfusions }\end{array}$ & 2.3 & 0.4 & 2.2 & 0.2 \\
\hline Lambert-Eaton syndrome & 1.2 & 0.2 & 0.7 & 0.1 \\
\hline
\end{tabular}

BMT: Bone Marrow Transplantation 
Table 4 IGIV prescriptions in the most frequent non-accepted indications

\begin{tabular}{|c|c|c|c|c|}
\hline \multirow[t]{2}{*}{ Indications } & \multicolumn{2}{|l|}{ Patients } & \multicolumn{2}{|l|}{ Prescriptions } \\
\hline & $\begin{array}{l}\text { Non-authorised non-accepted } \\
\text { indications }(n=133)(\%)\end{array}$ & $\begin{array}{l}\text { All indications } \\
(n=554)(\%)\end{array}$ & $\begin{array}{l}\text { Non-authorised non-accepted } \\
\text { indications }(n=197)(\%)\end{array}$ & $\begin{array}{l}\text { All indications } \\
(n=1,287)(\%)\end{array}$ \\
\hline Multiple sclerosis & 11.3 & 2.7 & 10.6 & 1.6 \\
\hline Bullous dermatosis & 7.5 & 1.8 & 9.1 & 1.4 \\
\hline Transplanted organ complications & 7.5 & 1.8 & 7.6 & 1.2 \\
\hline $\begin{array}{l}\text { Rheumatoid arthritis and other } \\
\text { inflammatory polyarthropathies }\end{array}$ & 3.7 & 0.9 & 6.6 & 1.0 \\
\hline $\begin{array}{l}\text { Other malignant neoplasias: histiocytic } \\
\text { and lymphoid tissues }\end{array}$ & 3.7 & 0.9 & 4.6 & 0.7 \\
\hline $\begin{array}{l}\text { Purpura and other haemorraghic } \\
\text { conditions }\end{array}$ & 5.3 & 1.3 & 4.6 & 0.7 \\
\hline $\begin{array}{l}\text { Peripheral neuropathy: hereditary and } \\
\text { idiopathic }\end{array}$ & 5.3 & 1.3 & 4.6 & 0.7 \\
\hline Horn cells disease & 4.5 & 1.1 & 4.6 & 0.7 \\
\hline Chronic glomerulonephritis & 3.7 & 0.9 & 3.5 & 0.6 \\
\hline Immune disorders & 5.3 & 1.3 & 3.5 & 0.5 \\
\hline $\begin{array}{l}\text { Encephalitis, myelitis and } \\
\text { encephalomyelitis }\end{array}$ & 4.5 & 1.1 & 3.5 & 0.5 \\
\hline
\end{tabular}

indications with scientific support and 197 (15\%) for nonauthorised and non-accepted indications.

The authorised indications group (group 1) is presented in the Table 2. The most frequently authorised indications were primary $(30.5 \%$ of patients and $43 \%$ of total prescriptions) and secondary immunodeficiencies $(16.8 \%$ of patients and $21.4 \%$ of total prescriptions). The levels of IG were measured in $255(46 \%)$ of a total of 554 prescriptions for primary immunodeficiencies. Of these prescriptions, in $79(30 \%)$ cases, IG levels were below the recommended range $(<600 \mathrm{mg} / \mathrm{dl})$ for IVIG administration.

The non-authorised indications with scientific evidentiary support (group 2) are presented in Table 3. The most frequent were motor multifocal neuropathy $(3.8 \%$ of patients and $3.3 \%$ of total prescriptions), myasthenia gravis $(4.5 \%$ of patients and $2.6 \%$ of total prescriptions) and chronic inflammatory demyelinating polyradiculopathy $(3.4 \%$ of patients and $2.1 \%$ of total prescriptions).
The non-authorised and non-accepted indications (group 3 ) are presented in Table 4 . The most frequent non-accepted indications were multiple sclerosis $(2.7 \%$ patients and $1.6 \%$ of total prescriptions), bullous dermatosis ( $1.8 \%$ patients and $1.4 \%$ of total prescriptions) and transplanted organ complications (1.8\% patients and $1.2 \%$ of total prescriptions).

According to Spanish legislation, 219 of the 554 patients included in the study needed an informed consent to comply with the compassionate use procedure. However, informed consent was requested in 26 patients $(12 \%)$ and the compassionate use procedure was only followed in 12 $(5.5 \%)$ of these patients. In only $592(46 \%)$ of the prescriptions was the administered lot number recorded in the clinical history of the patient.

At least one adverse drug reaction was described in 119 patients (21.4\%). In 28 patients (5\%) it was a serious adverse drug reaction, and in 16 patients the IVIG treatment was discontinued or the regimen modified due to the

Table 5 Cost of IVIG use according to the appropriateness of indications

\begin{tabular}{llr}
\hline Indications & \multicolumn{1}{l}{ Cost mean (SD) } \\
\cline { 2 - 3 } & Per patient $(€)$ & Per prescription $(€)$ \\
\hline Authorised & $2,636.2(2,085.5)$ & $928.8(1,027.3)$ \\
Non-authorised with scientific evidentiary support & $5,262.1(2,899)$ & $3,317.8(1,634.3)$ \\
Non-authorised non-accepted & $3,555.8(3,020.7)$ & $2,346.8(1,816.8)$ \\
Total & $3,260.6(2,435.7)$ & $1,398.7(1,502.4)$ \\
\hline
\end{tabular}

The total budget for IVIG treatments for the authorised indications was of $884,932.6 €(49.3 \%)$, for the non-authorised indications with scientific support $451,216.8 €(25.1 \%)$ and for the non-authorised and non-accepted indications $459,973.5 €(25.6 \%)$. 
Table 6 Characteristics of IVIG prescription across the hospitals

\begin{tabular}{|c|c|c|c|c|}
\hline $\begin{array}{l}\text { Hospital no. } \\
\text { ( } n \text { patients) }\end{array}$ & $\begin{array}{l}\text { Authorised } \\
\text { indications, } \\
n(\%)\end{array}$ & $\begin{array}{l}\text { Non- } \\
\text { authorised } \\
\text { indications } \\
\text { with } \\
\text { evidentiary } \\
\text { support, } \\
n(\%)\end{array}$ & $\begin{array}{l}\text { Non-authorised } \\
\text { and non- } \\
\text { accepted } \\
\text { indications, } \\
n(\%)\end{array}$ & $\begin{array}{l}\text { Total } \\
\text { prescriptions, } \\
n(\%)\end{array}$ \\
\hline $1(60)$ & $134(82.2)$ & $3(1.8)$ & $26(16.0)$ & $163(100)$ \\
\hline $2(173)$ & $423(82.5)$ & $9(1.8)$ & $81(15.8)$ & $513(100)$ \\
\hline $3(51)$ & $62(49.2)$ & $37(29.4)$ & $27(21.4)$ & $126(100)$ \\
\hline $4(44)$ & $102(75.6)$ & $14(10.4)$ & $19(14.1)$ & $135(100)$ \\
\hline $5(11)$ & $6(46.2)$ & $3(23.1)$ & $4(30.8)$ & $13(100)$ \\
\hline $6(23)$ & $17(53.1)$ & $8(25.0)$ & 7 (21.9) & $32(100)$ \\
\hline $7(25)$ & $35(85.4)$ & $4(9.8)$ & $2(4.9)$ & $41(100)$ \\
\hline $8(40)$ & $29(46.0)$ & $13(20.6)$ & $21(33.3)$ & $63(100)$ \\
\hline $9(11)$ & $0(0.0)$ & $13(92.9)$ & $1(7.1)$ & $14(100)$ \\
\hline $10(42)$ & $53(62.4)$ & 15 (17.6) & $17(20.0)$ & $85(100)$ \\
\hline $11(8)$ & $9(75.0)$ & $2(16.7)$ & $1(8.3)$ & $12(100)$ \\
\hline $12(26)$ & $28(66.7)$ & $5(11.9)$ & 9 (21.4) & $42(100)$ \\
\hline $13(40)$ & $24(50.0)$ & $11(22.9)$ & $13(27.1)$ & $48(100)$ \\
\hline
\end{tabular}

adverse drug reaction. The most commonly reported adverse effects were general disorders and events at the administration site, followed by nervous system disorders, gastrointestinal disorders, musculoskeletal and connective tissue disorders, and skin and subcutaneous tissue disorders. The most frequent serious adverse drug reactions were headache, pyrexia, malaise, nausea, vomiting, asthenia, and back pain. In nine patients (1.6\%), IVIG treatment was withdrawn for lack of effectiveness.

The total budget for IVIG treatment during the period of the study was $1,794,494 €$. The mean (SD) cost of IVIG treatment per patient in the study was $3,260.6 €(2,435.7 €)$ and per prescription was $1,398.7 €(1,502.4 €)$. Table 5 shows the cost of IVIG use according to the appropriateness of indications. The mean (SD) cost of IVIG per prescription and per patient for group 2 and group 3 was higher than for group 1 . The indications with highest mean cost per prescription were Guillain-Barré syndrome, followed by dermatomyositis, chronic inflammatory demyelinating polyneuropathy and motor multifocal neuropathy.

Table 6 shows the differences in IVIG prescriptions between hospitals. A great variability was observed among the number of treated patients, number of prescriptions and the appropriateness of indications between hospitals. The mean (SD) cost per prescription between hospitals ranged from $919.4 €(1,158 €)$ to $4,223.8 €(1,490.2 €)$. The recording of lot numbers also ranged from some settings in which it was $100 \%$, down to hospitals where the lot number was never registered.

\section{Discussion}

The results of the study show that $40 \%$ of patients treated with IVIG and almost a third of prescriptions were for offlabel indications. Figures for the non-authorised and nonaccepted indications were 24 and $15 \%$ respectively of the total treated patients and prescriptions. Other IVIG utilisation studies have been reported, but this particular study has the highest number of included patients.

The percentage of IVIG use for off-label indications described in other multicentre drug utilisation studies ranged from 62.9 to $20 \%$ [8-10]. In a study where IVIG use was monitored over a period of 2 years (2003-2005) in 339 patients from four Canadian Atlantic provinces, 62.9\% prescriptions were for off-label indications [8]. This rate was $52 \%$ in another study from 12 U.S. academic health centres [9], where data from 251 patients were prospectively collected during 8 months in 1996, and it was only $20 \%$ in a retrospective study from four Toronto teaching hospitals carried out in 429 patients over a 6-year period (1995-2000) [10]. At the same time, the percentage of non-authorised and non-accepted IVIG prescriptions described in the present study was higher than that described in the American study (14\% of treated patients) [9] and in the study from four teaching hospitals in Canada (8.4\% of the indications) [10].

These differences cannot be explained by a variance in the prevalence of the diseases between countries. The lack of a well established treatment for the majority of these severe diseases could explain the use of drugs with scarce evidence in settings where a consensus protocol is not available.

In this study, as in those mentioned above, the neurologists and the haematologists were the leading prescribing specialists of IVIG $[8,10]$. However, in our study a relevant difference was the high prescription of IVIG by pneumologists.

Primary and secondary immunodeficiencies were the most frequently labelled indications in this study. It is generally agreed that IVIG is useful for these conditions and their administration is recommended when plasma levels of IG are below $600 \mathrm{mg} / \mathrm{dl}[6,7]$. During the study period, IG plasma levels were measured quite frequently but IVIG was often administered even if the IG levels were above the levels for which IVIG administration is recommended. In the American and Canadian studies, immunodeficiencies also represented the most frequent labelled indications, but idiopathic thrombocytopenic purpura was the most frequent [8-10]. In this condition IVIG therapy was established as an immunomodulatory alternative when steroids fail to increase the platelet count [2].

The neurological conditions (motor multifocal neuropathy, myasthenia gravis and chronic inflammatory demyelinating polyradiculopathy) were the most frequent non-authorised 
indications with scientific support in the study. In several randomized controlled trials, IVIG therapy improved some features of these conditions and was increasingly preferred to steroids or plasma exchange, especially for motor multifocal neuropathy and chronic inflammatory demyelinating polyradiculopathy therapy [2]. However, the EMEA is requesting further clinical studies for approval of IVIG use in these immunomodulatory indications [1]. In the American and the Canadian studies, chronic inflammatory demyelinizing polyradiculopathy was the most frequent non-authorised indication with scientific support [8-10]. Guillain-Barré syndrome was another frequent non-authorised indication with scientific support in the US and Canadian studies [8-11]. However, Guillain-Barré syndrome is a label indication in Europe, and therefore, in this study was included as an authorised indication.

Multiple sclerosis, bullous dermatosis and transplanted organ complications were the most frequent non-authorised and non-accepted indications in this study. The percentage of patients with IVIG therapy for non-authorised and nonaccepted indications described in our study was higher than that reported in the other studies. However, the percentage of non-authorised and non-accepted indications per prescription was lower due to the high proportion of patients with immunodeficiencies in the study and the elevated frequency of IVIG administration in these patients throughout the study. All these conditions, with the exception of multiple sclerosis, which was classified as a non-authorised indication with scientific support in the Canadian studies [8], also appeared on the list of the most frequently non-authorised and non-accepted indications in the other studies. A Cochrane review of IVIG in multiple sclerosis concluded that while there is some scientific evidence to support its use in relapsing-remitting disease, there is a need for further studies to establish more robust conclusions [24].

The relevance of IVIG prescriptions for non-authorised and non-accepted indications lies in the increase that has been described over the last few years; the situation is dramatic when a period of product shortage occurs [2-5]. On the other hand, IVIG is a haemoderivative product and its administration for these conditions submits patients to some risk [2-5]. Finally, the economic consequences are also relevant. In our study, the mean cost per prescription and per patient was higher for the non-authorised indications with scientific support and the non-authorised and non-accepted indications than for the authorised indications. The economic implications of IVIG use have only been assessed in a few studies. Constantine et al. reported that a $4.2 \%$ reduction in unlabelled IVIG use in indications not supported by evidence was associated with a $\$ 153,799$ reduction in cost during their 2-year project [8]. In our study, if IVIG had not been prescribed for the non- authorised and non-accepted indications, then a reduction in cost of $459,973.52 €(25.6 \%$ of the total budget $)$ would have been produced during the study period. In another study from the Massachusetts General Hospital, the annual cost of IVIG use for chronic neuropathies (chronic inflammatory demyelinating polyneuropathy and multifocal motor neuropathy) exceeded $\$ 50,000$ per patient [11]. In our study, the mean cost per patient for these diseases was less, being $5,445.1 €(1,779.6 €)$ to treat chronic inflammatory demyelinating polyneuropathy and $6,854.0 €$ $(3,782.2 €)$ to treat multifocal motor neuropathy over the 3 months of the study.

On the other hand, only on a few occasions was informed consent requested and compassionate use regulations followed in cases where Spanish legislation made this necessary. This behaviour may involve some legal consequences for medical doctors, especially if an adverse reaction appears with the administered haemoderivative product for an unlabelled indication without scientific support. Nevertheless, the Spanish legislation for compassionate use has recently changed and now includes only the requirement for compliance with the protocol for uses of an investigational medicinal product in a patient outside a clinical trial.

Finally, great variability was observed in the IVIG prescription appropriateness between hospitals. It is interesting to note that two appropriateness patterns of prescription were observed. In some hospitals most of the IVIG prescriptions were for authorised indications, and in other hospitals the percentage of IVIG prescriptions for authorised and non-authorised indications was similar. A study carried out in a single tertiary Spanish hospital, and not included in our study, reported a percentage of prescriptions for labelled indications of $85.8 \%$, similar to one of the prescription patterns mentioned above, and most were for primary immunodeficiencies [12]. This hospital variability may be due, at least in part, to the heterogeneity of the hospitals (i.e. size of the hospitals, medical specialities and treated pathologies). Unfortunately, no information on IVIG prescription differences between hospitals was included in the other multicentre published studies.

One of the main limitations of our study is whether the results are representative of IVIG prescription in Spain, as a random sample of hospitals was not selected. However, IVIG are usually used in tertiary hospitals similar to those included in our study. Another limitation is the variability in the categories where some indications are classified. Guillain-Barré syndrome and multiple sclerosis are classified as non-authorised indications with scientific support in some recommendations $[15,16]$. In our study, these misclassifications would have slightly increased the percentage of IVIG prescriptions for the non-authorised indications with scientific support to $23.4 \%$ per patient and $15.4 \%$ per 
prescription and slightly decreased the corresponding percentages for the authorised indications to $56 \%$ per patient and $72.4 \%$ per prescription, and the nonauthorised and non-accepted indications to $21 \%$ per patient and $13.4 \%$ per prescription, respectively. In addition, another limitation may be that the study was conducted 5 years ago; however, the findings are still in line with the present situation because significant changes regarding IVIG use have not happened in Spanish hospitals during this period.

Despite these limitations, the results of this study show that in Spain, a significant percentage of IVIG prescriptions are for indications without scientific support. This fact is even more important because the administration of IVIG is associated with some risks, its production is very limited with recurrent periods of shortage, and it has a high cost. Therefore, the Spanish Society of Clinical Pharmacology considers the elaboration of protocol agreements of IVIG use to be of great interest and believes that the results of this study, which describes IVIG utilisation in our country, are essential and confirm that a consensus statement is needed. A proposed consensus committee would imply the involvement of the following interested parties: health authorities, prescribing physicians (haematologists, neurologists, internal medicine specialists), pharmacists and clinical pharmacologists.

To provide an example, national Clinical Guidelines for IVIG use have been available in the United Kingdom since 2007, have been recently revised in a second edition [33], and local hospitals are required to complete audit forms for monitoring the use of IVIG according to the Clinical Guidelines. The goal of this interesting initiative, supported by the Department of Health, is to provide guidance on appropriate use, to manage demand and to ensure supply for patients for whom IGIV is life-saving.

In conclusion, this extensive nationwide study on IVIG prescribing describes a high proportion of off-label prescriptions and highlights the need to provide national clinical guidelines for IVIG use.

\section{Appendix}

The following persons participated in the study: Maria Oliveras Arenas, Aurora Fernández Polo, Xavier Carné, Nuria Cruz, Francesc Jané Carrencà, Anna Vaqué, Anabel Barriocanal, Cristina Campo Hoyos, Marta Valero Domínguez, Antonio Portoles, Aithana Calvo, $\mathrm{M}^{\mathrm{a}}$ Ángeles Geniz Clavijo, José Luis Hernández Galán, Carmen María Jiménez, Mónica Saldaña, María Laura Peregrina, Lourdes Cabrera García, Arantxa Sancho López, Maria José Pedrosa Martinez, Isabel Salcedo de Diego, José Ramón Azanza Perea, Julia Nazco Casariego, Mar García-Sáiz.

\section{References}

1. Farrugia A, Poulis P (2001) Intravenous immunoglobulin: regulatory perspectives on use and supply. Transfusion Med 11:63-74

2. Jolles S, Sewell WAC, Misbah SA (2005) Clinical uses of intravenous immunoglobulin. Clin Exp Immunol 142:1-11

3. Dalakas MC (2004) The use of intravenous immunoglobulin in the treatment of autoimmune neuromuscular diseases: evidence-based indications and safety profile. Pharmacol Ther 102:177-193

4. Siegel J (2005) The product: all intravenous immunoglobulins are not equivalent. Pharmacother $25: 78 \mathrm{~s}-84 \mathrm{~s}$

5. Chapel HM (1999) Safety and availability of immunoglobulin replacement therapy in relation to potentially transmissable agents. IUIS Committee on Primary Immunodeficiency Disease. International Union of Immunological Societies. Clin Exp Immunol 118(Suppl 1):29-34

6. Committee for Proprietary Medicinal Products (CPMP) (2000) Core SPC for human normal immunoglobulin for intravenous administration (IVIg). CPMP/BPWG/859/95 rev 1

7. Committee for medicinal products for human use (CHMP) (2004) Core SPC for human normal immunoglobulin for intravenous administration (IVIg). CPMP/BPWG/859/95 rev 2. EMEA, London

8. Constantine MM, Thomas W, Whitman L, Kahwash E, Dolan S, Smith S, Caudle CJ Burton E, Anderson DR (2007) Intravenous immunoglobulin utilization in the Canadian Atlantic provinces: a report of the Atlantic Collaborative Intravenous Immune Globulin Utilization Working Group. Transfusion 47:2072-2080

9. Chen C, Danekas LH, Ratko TA, Vlasses PH, Matuszewski KA (2000) A multicenter drug use surveillance of intravenous immunoglobulin utilization in US academic health centers. Ann Phamacother 34:295-299

10. Pendergrast JM, Sher GD, Callum JL (2005) Changes in intravenous immunoglobulin prescribing patterns during a period of severe product shortages, 1995-2000. Vox Sang 89:150-160

11. Darabi K, Abdel-Wanab O, Dzik WH (2006) Current usage of intravenous immune globulin and the rationale behind it: the Massachusetts General Hospital data and a review of the literature. Transfusion 46:741-753

12. Perayre M, Pastó L, Jódar R (2006) Changes in the pattern of intravenous immunoglobulin use over a 5-year period. Eur J Hosp Pharm Sci 12:67-71

13. Ley $29 / 2006$, de 26 de julio, de garantías y uso racional de los medicamentos y productos sanitarios" (2006) http://sescam.jccm. es/web1/ciudadanos/elSescam/legislacion/Ley29_2006_Farmacia. pdf. Accessed 6 Sept 2009

14. [No authors listed] (1999) Primary immunodeficiency diseases. Report of an IUIS Scientific Committee International Union of Immunological Societies. Clin Exp Immunol 118(Suppl 1):1-28

15. Ratko TA, Burnett DA, Foulke GE, Matuszewski KA, Sacher RA (1995) Recommendations for off-label use of intravenously administered immunoglobulin preparations. University Hospital Consortium Expert Panel for off-label use of polyvalent intravenously administered immunoglobulin preparations. JAMA 273:1865-1870

16. Consensus Working Group (1997) Present and future uses of IVIG. A Canadian multidisciplinary consensus building initiative. Can J Allergy Clin Immunol 5:176-208

17. The American Society of Hematology ITP Practice Guideline Panel (1997) Diagnosis and treatment of idiopathic thrombocytopenic purpura; recommendations of the American Society of Hematology. Ann Intern Med 126:319-326

18. Bril V, Allenby K, Midroni G, O'Connor PW, Vajsar J (1999) IGIV in neurology: evidence and recomendations. Can J Neurol Sci 26(2):139-152 
19. Dalakas MC (1999) Intravenous immune globulin in the treatment of autoimmune neuromuscular disease: present status and practical therapeutics guidelines. Muscle Nerve 22:1479-1497

20. Fergusson D, Hutton B, Sharma M, Tinmouth A, Wilson K, Cameron DW, Hebert PC (2005) Use of intravenous immunoglobulin for treatment of neurologic conditions: a systematic review. Transfusion 45:1640-1657

21. Hughes RA, Raphaël JC, Swan AV, Doorn PA (2004) Intravenous immunoglobulin for Guillain-Barré syndrome. Cochrane Database Syst Rev 1: CD002063

22. Van Schaik IN, Winer JB, De Haan R, Vermeulen M (2002) Intravenous immunoglobulin for chronic inflammatory demyelinating polyradiculoneuropathy. Cochrane Database Syst Rev 2:CD001797

23. Joint Task Force of the EFNS and the PNS (2005) European Federation of Neurological Societies/Peripheral Nerve Society Guideline on management of chronic inflammatory demyelinating polyradiculoneuropathy. Report of a joint task force of the European Federation of Neurological Societies and the Peripheral Nerve Society. J Peripher Nerv Syst 10:220-228

24. van Schaik IN, van den Berg LH, de Haan R, Vermeulen M (2005) Intravenous immunoglobulin for multifocal motor neuropathy. Cochrane Database Syst Rev 2:CD004429

25. Gray O, McDonnell GV, Forbes RB (2003) Intravenous immunoglobulins for multiple sclerosis. Cochrane Database Syst Rev 3: CD002936
26. Maddison P, Newsom-Davis J (2003) Treatment for Lambert-Eaton myasthenic syndrome. Cochrane Database Syst Rev 2:CD003279

27. Göttfried I, Seeber A, Anegg B, Rieger A, Stingl G, Volc-Platzer B (2000) Highdose intravenous immune globulins in dermatomyositis: clinical responses. Eur J Dermatol 10:29-35

28. Beck CE, Nathan PC, Parkin PC, Blanchette VS, Macarthur C (2005) Corticosteroids versus intravenous immune globulin for the treatment of acute immune thrombocytopenic purpura in children: a systematic review and meta-analysis of randomized controlled trials. J Pediatr 147:521-527

29. Jenson HB, Pollock BH (1997) Meta-analyses of the effectiveness of intravenous immune globulin for prevention and treatment of neonatal sepsis. Pediatrics 99(2):e2

30. Haque KN (2000) Intravenous immunoglobulins versus sepsis. Pediatrics 105:1173

31. Ohlsson A, Lacy J (2004) Intravenous immunoglobulin for suspected or subsequently proven infection in neonates. Cochrane Database Syst Rev 1:CD001239

32. Ohlsson A, Lacy J (2004) Intravenous immunoglobulin for preventing infection in preterm and/or low-birth-weight infants. Cochrane Database Syst Rev 1:CD000361

33. Provan D, Nockes TJC, Agrawal S, Winer J, Wood P (2008) Clinical guidelines for immunoglobulin use, 2nd ed. UK Department of Health, London. http://www.dh.gov.uk/en/Publicationsandstatistics/ Publications/PublicationsPolicyAndGuidance/DH_085235 